\title{
Comparison Of The Clinical Outcomes Of Primary Closure And Patch Plasty Techniques In Carotid Endarterectomy
}

\section{Karotis Endarterektomisinde Primer Kapanma ve Yama Plastiği Tekniklerinin Klinik Sonuçlarının Karşılaştırılması}

\author{
Muhammet Bozguney' ${ }^{1}$, Rifat Ozmen $^{2}$, Tamer Eroglu $^{3}$, Aydin Tuncay $^{2}$, Deniz Elcik $^{4}$ \\ 'Adana City Hospital, Department of Cardiovascular Surgery, Adana, Turkey \\ ${ }^{2}$ Erciyes University Medicine Faculty, Department of Cardiovascular Surgery, Kayseri, Turkey \\ ${ }^{3}$ Ömer Halis DemirUniversity School of Medicine Department of Cardiovascular Surgery, Niğde, Turkey \\ ${ }^{4}$ Erciyes University Medicine Faculty, Department of Cardiology, Kayseri, Turkey
}

\begin{abstract}
Background: In this study, patients undergoing carotid endarterectomy with primary closure or patch angioplasty for carotid artery disease were evaluated retrospectively and our early results were presented.

Methods: In our clinic, fifty-five patients who performed carotid endarterectomy for carotid artery disease between November 2013 and May 2017 were enrolled in the study. The files of patients were reviewed retrospectively. These patients were divided into two groups as Group 1 (primer closure group, $\mathrm{n}=32$ ) and Group 2 (patch angioplasty group, $\mathrm{n}=23$ ). Both groups were compared in terms of demographic data, surgical technique, complications, and early results.

Results: There were no statistically significant differences in terms of intensive care unit stay and hospitalization, postoperative neck hematoma/exploration, postoperative renal failure, and the other demographic data, symptomatology, surgical technique, $\geq 30$-day stroke, $\geq 30$ day restenosis, $\geq 30$-day death between both groups.

Conclusion: Our study results have shown that the closure of arteriotomy with primary or patch angioplasty after carotid endarterectomy is a safe method in terms of early results.
\end{abstract}

Keywords: Carotid endarterectomy, angioplasty, carotid artery stenosis, mortality
Öz

Amaç: Bu çalışmada karotis arter hastalığı için primer kapama veya yama anjiyoplasti ile karotis endarterektomi uygulanan hastalar retrospektif olarak değerlendirildi ve erken sonuçlarımız sunuldu.

Yöntemler: Kliniğimizde Kasım 2013-Mayıs 2017 tarihleri arasında karotis arter hastalığı için karotis endarterektomi uygulanan elli beş hasta çalışmaya dahil edildi. Hasta dosyaları retrospektif olarak incelendi. Bu hastalar Grup 1 (primer kapatma grubu, $n=32$ ) ve Grup 2 (yama anjiyoplasti grubu, $n=23$ ) olarak iki gruba ayrıldı. Her iki grup demografik veriler, cerrahi teknik, komplikasyonlar ve erken sonuçlar açısından karşılaştırıldı.

Bulgular: Iki gurup arasında yoğun bakımda kalış ve hastaneye yatış, postoperatif boyun hematomu / eksplorasyonu, postoperatif böbrek yetmezliği, semptomatoloji, 30 günlük inme, 30 günlük restenoz , 30 günlük ölüm açısından anlamlı fark tespit edilmedi.

Sonuç: Arteriyotominin karotis endarterektomi sonrası primer veya yama anjiyoplasti ile kapatılmasının erken sonuçlar açısından güvenli bir yöntem olduğunu göstermiştir.

Anahtar Kelimeler: Karotis endarterektomi, anjiyoplasti, karotis arter stenozu, mortalite 


\section{INTRODUCTION}

Carotid artery disease (CAD) is one of the most important causes of stroke. Currently, carotid endarterectomy (CEA) is accepted as the gold standard treatment option for severe carotid artery stenosis (CAS). ${ }^{[1]} \mathrm{A}$ number of studies demonstrated that CEA can reduce the rates of stroke and death in patients with internal carotid artery stenosis independent of symptom status. ${ }^{[2]}$

Eastcott and colleagues ${ }^{[3]}$ reported the first case of successful surgical intervention to CAS in 1954. Several studies suggested that surgical treatment of the carotid stenosis is superior to medical treatment with respect to preventing cerebrovascular complications and increasing quality of life in patients with severe CAS. ${ }^{[2,4]}$

A number of techniques are proposed to patch up the arteriotomy after CEA operation, and they are primer closure, prosthetic patch angioplasty, venous patch angioplasty, or biomaterial patch angioplasty. ${ }^{[5]}$ Of these techniques, the patch angioplasty is commonly performed after carotid endarterectomy. In fact, patch angioplasty is standard practice due to its relation to lower rates of carotid restenosis and stroke. ${ }^{[5-7]}$ Although there are a number of different approaches, currently, there is no consensus about the optimal method of arteriotomy closure after the carotid endarterectomy.

In the present study, we aimed to compare the clinical outcomes of the primer closure and the patch angioplasty for the carotid endarterectomy.

\section{MATERIAL AND METHOD}

A total of 55 patients (37 males and 18 females; the mean age was 70.9 years) data, who underwent the carotid endarterectomy between November 2013 and May 2017 at Kayseri City Training and Educational Hospital were evaluated retrospectively. The Local Clinical Research Ethical Committee approved the protocol of the current study. Due to the retrospective nature of the current study, the requirement for written informed consent was waived by the committee.

Demographic data and comorbid conditions of each patient were recorded. The patients included in the current study were divided into two groups: Group 1 (primer closure (PC) group, $\mathrm{n}=32$ ), and Group 2 (patch angioplasty (PA) group, $n=23$ ). The 15 patients $(27.3 \%)$ were neurologically asymptomatic, whereas the $40(72.7 \%)$ patients had neurologic symptoms related to carotid stenosis before the surgery. The neurologic symptoms were defined as TIA or stroke within six months before the surgery. All the patients were examined by means of carotid artery ultrasound and computed tomographic angiography (CTA) or magnetic resonance angiography (MRA) or conventional digital subtraction angiography (DSA) to assess the degree of carotid stenosis. The carotid endarterectomy was performed when the carotid artery stenosis was $\geq 60 \%$ in asymptomatic patients and $\geq 50 \%$ in symptomatic patients. The patch angioplasty was performed with a Dacron patch or bovine pericardial patch in Group 2. We used the processed bovine pericardial patch for the patients, who underwent CEA with the biological patch (Lemaitre Vascular, Inc, Burlington MA 01803, USA). The patch was washed with sterile saline solution, following the manufacturer's instructions prior to use. The Dacron patch used almost exclusively was the Hemashield Platinum Finesse (Maquet Cardiovascular, Inc, Wayne, NJ, USA). Standard dual antiplatelet therapy (acetylsalicylic acid 100 $\mathrm{mg} /$ day and clopidogrel $75 \mathrm{mg} /$ day) was routinely ordered following the carotid endarterectomy on postoperative day one. Postoperative neck hematoma/exploration, acute kidney injury, length of hospital stay (days), ICU stay (day), duration of surgical procedure (minutes), rates of 30-day stroke, and 30-day mortality were assessed for each surgical procedure performed. Postoperative stroke was described as any major neurologic deficit confirmed by the clinical judgment of the attending physician and/or results of a brain $\mathrm{CT}$. The restenosis was described as the presence of significant stenosis in the operated carotid artery ( $\geq 50 \%$ stenosis at the endarterectomy site with Doppler ultrasound study).

\section{Surgical Procedure}

All the patients included in this study underwent a standard carotid endarterectomy surgery under general anesthesia. In some cases, coronary artery bypass grafting (CABG) was carried out along with CEA, which was performed before CABG. After the longitudinal incision was made along the anterior border of the sternocleidomastoid muscle, the subcutaneous tissues were passed, and then the carotid sheath was reached. After the carotid sheath was opened, the common carotid artery, internal and external carotid arteries, and superior thyroid artery were exposed and isolated. The carotid bulb was injected with $1 \%$ lidocaine hydrochloride, which affects the carotid baroreceptor and prevents reflex sympathetic bradycardia. A bolus of 5000 IU heparin was administered intravenously for systemic anticoagulation before clamping the carotid arteries. A longitudinal arteriotomy was performed after systemic heparinization. Afterward, the carotid endarterectomy was performed. The arterial wall was irrigated with a heparinized saline solution. After the atheromatous plaque was completely removed, tacking sutures were placed proximally and distally unless no ledge was evident at either end of termination of the endarterectomy. We measured the pressure of the carotid stump in all the patients. The carotid stump pressure was maintained above $40 \mathrm{mmHg}$ and an inotropic drug was administrated, if necessary. Cerebral Oximeter was not used to evaluate cerebral oxygenation in all the patients. The CEA procedures were performed without shunting. The arteriotomy was closed either as primary or with a patch including Dacron or bovine pericardial patch. Primer arterial closure or prosthetic patch angioplasty were performed regardless of the size of the ICA in all cases.

\section{Statistical analysis}

Descriptive data derived from the results of the present study were presented as mean \pm standard deviation or median- 
interquartile range depending on the distribution type of the continuous variables. Categorical variables were summarized as number and percentage. Kolmogorov-Smirnov test was used to check the normality of the numeric variables. Depending on the patient groups studied, Fisher Exact test was utilized for comparisons of categorical variables, whereas independent samples $t$-test and Mann Whitney $U$ test were used to compare continuous variables when data are normally and non-normally distributed, respectively. Jamovi (jamovi project (2018). jamovi (Version 1.0.7) [Computer Software]) retrieved from https://www.jamovi.org) and JASP Team (2018, Version 0.10.2 [Computer Software]) were used to perform statistical analyses. A p value $(<0.05)$ was considered statistically significant.

\section{RESULTS}

The study aims to compare the clinical outcomes of surgical techniques, primer closure, and patch angioplasty with different patch materials, performed after CEA. The demographic characteristics of the patients were summarized in Table 1. There was no significant difference between the patient groups in terms of demographic characteristics, frequencies of chronic coexisting disorders, stroke, and transient ischemic attacks (TIA).

\begin{tabular}{|c|c|c|c|c|}
\hline Variables & $\begin{array}{l}\text { Whole Group } \\
(n=55)\end{array}$ & $\begin{array}{l}\text { PC group } \\
(n=3)\end{array}$ & $\begin{array}{l}\text { PA group } \\
(\mathrm{n}=32)\end{array}$ & $\begin{array}{c}p \\
\text { value }\end{array}$ \\
\hline Age (years), Mean $\pm S D$ & $70.93 \pm 9.16$ & $70.61 \pm 8.59$ & $71.16 \pm 9.67$ & 0.829 \\
\hline Gender, male, n (\%) & $37(67.3)$ & $14(60.9)$ & $23(71.9)$ & 0.561 \\
\hline Hyperlipedemia, n (\%) & $21(38.2)$ & $6(26.1)$ & $15(46.9)$ & 0.162 \\
\hline Diabetes mellitus, n (\%) & $38(69.1)$ & $18(78.3)$ & $20(62.5)$ & 0.25 \\
\hline Hypertension, n (\%) & $2(3.6)$ & $0(0)$ & $2(6.3)$ & 0.504 \\
\hline COPD, n (\%) & $11(20)$ & $4(17.4)$ & $7(21.9)$ & 0.745 \\
\hline Smoking, n (\%) & $14(25.5)$ & $7(30.4)$ & $7(21.9)$ & 0.472 \\
\hline CKD history, n (\%) & $4(7.3)$ & $1(4.3)$ & $3(9.4)$ & 0.479 \\
\hline ASO, n (\%) & $1(1.8)$ & $0(0)$ & $1(3.1)$ & 0.392 \\
\hline CAD, n (\%) & $29(52.7)$ & $15(65.2)$ & $14(43.7)$ & 0.116 \\
\hline TIA, n (\%) & $18(32.7)$ & $5(21.7)$ & $13(40.6)$ & 0.141 \\
\hline Stroke, n (\%) & $23(41.8)$ & $11(47.8)$ & $12(37.5)$ & 0.444 \\
\hline $\begin{array}{l}\text { ASO: arteriosclerosis oblit } \\
\text { chronic obstructive pulmo } \\
\text { Descriptive statistics for } n \\
\text { Samples t test was used fo } \\
\text { number (\%) and Fisher Exa }\end{array}$ & $\begin{array}{l}\text { D: coronary } \\
\text { ase; SD: Stan } \\
\text { istributed v ve vat } \\
\text { son. Descrip }\end{array}$ & 50 & chio & $\begin{array}{l}\text { COPD: } \\
\text { endent } \\
\text { iven as }\end{array}$ \\
\hline
\end{tabular}

Right-sided CEA was performed in 22 cases (40\%), while leftsided CEA was performed in 33 cases (60\%). In group 2, the bovine pericardial patch was used in 11 patients and the Dacron patch was used in 12 patients for patch angioplasty. Of all the patients, 15 patients (86.5\%) were asymptomatic and 40 patients $(72.7 \%)$ had neurologic symptoms.

A total of five patients developed several complications related to CEA. One patient underwent postoperative neck exploration due to surgical site hematoma, one patient developed acute kidney injury, and three patients had stroke over 30 days after CEA. There was no difference between PC and PA groups with regard to the developed complications. In general, restenosis was detected in three patients, and in this respect, the repeat groups did not show any meaningful difference. The carotid stenosis was determined to be $50 \%$ in three patients with restenosis. Therefore, these patients were followed up with medical treatment. None of the operated patients had contralateral severe carotid artery stenosis. Over 30 days postoperation, the mortality rate was $5.5 \%$ and there was no difference between the groups. Perioperative patient characteristics and complication rates were presented in Table 2.

\begin{tabular}{|c|c|c|c|c|}
\hline $\begin{array}{l}\text { Complication rates } \\
\text { and perioperative } \\
\text { characteristics }\end{array}$ & $\begin{array}{l}\text { Whole } \\
\text { group } \\
(\mathrm{n}=55)\end{array}$ & $\mathrm{PA}(n=23)$ & $\mathrm{PC}(\mathrm{n}=32)$ & p-value \\
\hline Asymptomatic, n (\%) & $15(27.3)$ & $8(34.8)$ & $7(21.9)$ & 0.289 \\
\hline Symptomatic, n (\%) & $40(72.7)$ & $15(65.2)$ & $25(78.1)$ & 0.363 \\
\hline 30-Day Death, n (\%) & $3(5.5)$ & $1(4.3)$ & $2(6.2)$ & 0.759 \\
\hline $\begin{array}{l}\text { Preoperative LMWH } \\
\text { Therapy, n (\%) }\end{array}$ & $6(10.9)$ & $1(4.3)$ & $5(15.6)$ & 0.186 \\
\hline $\begin{array}{l}\text { Preoperative Statin } \\
\text { Therapy, } \mathrm{n}(\%)\end{array}$ & $16(29.1)$ & $7(30.4)$ & $9(28.1)$ & 0.852 \\
\hline $\begin{array}{l}\text { Preoperative } \beta \text {-Blocker } \\
\text { Therapy, } \mathrm{n}(\%)\end{array}$ & $20(36.4)$ & $10(43.5)$ & $10(31.2)$ & 0.352 \\
\hline $\begin{array}{l}\text { Preoperative } \\
\text { Antiplatelet Therapy, } \\
\mathrm{n}(\%)\end{array}$ & $7(12.7)$ & $3(13)$ & $4(12.5)$ & 0.952 \\
\hline $\begin{array}{l}\text { Preoperative Myocardial } \\
\text { Infarction, } \mathrm{n}(\%)\end{array}$ & $8(14.5)$ & $5(21.7)$ & $3(9.4)$ & 0.200 \\
\hline $\begin{array}{l}\text { Length of Hospital Stay } \\
\text { (days), } \mathrm{n}(\%)\end{array}$ & $9.15 \pm 3.88$ & $9.30 \pm 3.85$ & $9.03 \pm 3.85$ & 0.800 \\
\hline $\begin{array}{l}\text { Length of ICU Stay } \\
\text { (days), Median [IQR] }\end{array}$ & $1[1-3]$ & $1[1-3]$ & $1[1-2.5]$ & 0.743 \\
\hline $\begin{array}{l}\text { Duration of operation } \\
\text { (minutes ), Mean, SD }\end{array}$ & $92.78 \pm 24.49$ & $95.74 \pm 25.70$ & $90.66 \pm 23.76$ & 0.453 \\
\hline CABG + CEA, n (\%) & $13(23.6)$ & $6(26.1)$ & $7(21.9)$ & 0.717 \\
\hline Right CEA, n (\%) & $22(40)$ & $10(43.5)$ & $12(37.5)$ & 0.655 \\
\hline Left CEA, n (\%) & $33(60)$ & $13(56.5)$ & $20(62.5)$ & 0.782 \\
\hline \multicolumn{5}{|l|}{ ASA classification, n (\%) } \\
\hline I & $2(3.6)$ & $1(4.3)$ & $1(3.1)$ & \multirow{4}{*}{0.078} \\
\hline$\|$ & $15(27.3)$ & $3(13)$ & $12(37.5)$ & \\
\hline III & $37(67.3)$ & 19 (82.6) & $18(56.3)$ & \\
\hline IV & $1(1.8)$ & $0(0)$ & $1(3.1)$ & \\
\hline $\begin{array}{l}\text { Postoperative neck } \\
\text { hematoma/exploration, } \\
\mathrm{n}(\%)\end{array}$ & $1(1.8)$ & $0(0)$ & $1(3.1)$ & 0.392 \\
\hline$\geq 30$-day stroke, n (\%) & $3(5.5)$ & $1(4.3)$ & $2(6.3)$ & 0.759 \\
\hline $\begin{array}{l}\text { Postoperative acute } \\
\text { kidney injury, } \mathrm{n}(\%)\end{array}$ & $1(1.8)$ & $0(0)$ & $1(3.1)$ & 0.295 \\
\hline $\begin{array}{l}\geq 30 \text {-day restenosis, } \\
\text { n (\%) }\end{array}$ & $3(5.5)$ & $1(4.3)$ & $2(6.3)$ & 0.905 \\
\hline$\geq 30$-day death, $\mathrm{n}(\%)$ & $3(5.5)$ & $1(4.3)$ & $2(6.3)$ & 0.905 \\
\hline
\end{tabular}

ASA: American Society of Anesthesiologists; ASO: arteriosclerosis obliterans; CABG: coronary artery bypass grafting; CEA: carotid endarterectomy; ICU: intensive care unit; IQR: Interquartile Range; SD:

Standart Deviation. Samples $t$ test was used for comparison. Descriptive statistics for variables that didn't have normal distribution were given as median [IQR] and Mann Whitney U test was used for comparison. Descriptive statistics for categorical variables were given as number (\%) and Fisher Exact test was used for comparison. 


\section{DISCUSSION}

This study compared retrospectively the rates of restenosis and stroke as well as other surgical complications in patients, who had undergone CEA either with primary closure or with patch angioplasty. The main finding of the current study was that there was no significant difference between the groups in terms of the restenosis, the stroke, or the other surgery-related complications. In contrast to the literature, the primary closure was not associated with increased perioperative stroke and restenosis rates in the current study.

Several studies indicated that the carotid endarterectomy reduces the risk of stroke and related mortality in patients with both the symptomatic and the asymptomatic CAS. ${ }^{[8,9]}$ Indications of treatment for carotid artery disease are determined by factors associated with the neurological symptoms, the degree of carotid stenosis, the presence of coexisting chronic diseases, the vascular and local anatomical features, and the carotid plaque morphology. ${ }^{[4]}$

The exact characterization of CAS with the appropriate imaging modalities is of crucial importance before the CEA performed. We used DUS as the first-line imaging modality for diagnosis. After deciding on the carotid endarterectomy, the CAS was confirmed by either CTA or MRA. The main advantage of the CTA or MRA compared to DUS is their ability to evaluate the aortic arch as well as the extra- and intracranial circulation. [10]

According to the 2017 guidelines of the European Society for Vascular Surgery (ESVS), the CAS is defined as 'symptomatic' if the patient had related symptoms in the preceding 6 months and 'asymptomatic' if no prior symptoms are seen or when symptoms have occurred $>6$ months before diagnosis. The CEA should be considered in patients with an asymptomatic $60-99 \%$ stenosis if the perioperative stroke/death rates are below 3\%, and the patient's life expectancy is greater than five years (Class Ila, Level B). In the symptomatic patients, who have $70-99 \%$ carotid stenosis, the documented procedural death/stroke rate is below $6 \%$ and the CEA is recommended (Class I, Level A). ${ }^{[10]}$

The CEA has remained the standard management strategy for severe carotid artery stenosis. In the present study, we preferred the conventional CEA rather than eversion endarterectomy for all the patients due to technical ease. When compared to the primary arterial closure, patch angioplasty is associated with fewer strokes and lower restenosis rates. ${ }^{[11,12]}$ Therefore, the patchplasty is now considered to be the standard of practice for the patients undergoing conventional CEA. Although a previous meta-analysis revealed that the patch angioplasty was associated with lower restenosis and perioperative stroke rates $^{[13]}$ a recent retrospective study performed by Huizing $E$ et al. ${ }^{[14]}$ questioned this assumption. These authors suggested that, in patients with symptomatic CAS, there was no difference in PA and PC groups in terms of restenosis, stroke, or death rates. ${ }^{[14]}$ After this study, Huizing $E$ et al. ${ }^{[14]}$ performed a meta-analysis based on moderate-quality trial data, and they found that perioperative stroke and restenosis rates were lower in the patients undergoing PA when compared to those undergoing PC. ${ }^{[15]}$ The meta-analysis of Huizing E et al. ${ }^{[14]}$ confirmed the results of previous meta-analyses, in which the PA was deemed safer when compared to the PC technique. As we could not detect a difference regarding to restenosis and stroke rates between the two procedures, the results of the current study were not in agreement with the meta-analysis results of Huizing $E$ et al. ${ }^{[14]}$ The lack of this difference might be due to the retrospective nature of the present study and a relatively small sample size.

The primary closure or the patch angioplasty decision is based in part on the anatomical features of the carotid artery. However, there is still no unanimous agreement in regarding to the selection of the closure method. The recent reports suggested that a patch angioplasty is indicated for the patients, whose internal carotid artery diameters are smaller than 4-5 $\mathrm{mm}$ to prevent perioperative stroke and occlusion. [16] Clagett and colleagues $^{[17]}$ reported that the primer closure method could be safely chosen in the anatomically appropriate patient groups due to their lower restenosis rates. The CEA operations were performed regardless of the size of the ICA at our Institution/Hospital.

The arteriotomy closure can be performed either with an autologous venous patch or synthetic materials such as Dacron, polytetrafluoroethylene (PTFE), bovine pericardium, and polyester urethane. ${ }^{[6,18]}$ When compared to prosthetic patches, bovine pericardial patches have several advantages, which are more biocompatible, easy to handle, associated with less suture line bleeding, and possibly have reduced infection risk. ${ }^{[19]}$ These advantages of bovine pericardium lead to its widespread use during the CEA. In this context, we also used a Dacron patch and a bovine pericardial patch and obtained similar results.

The use of shunting during the carotid endarterectomy (CEA) to prevent the development of stroke is still controversial. Although some studies supported the use of shunting, others suggested that there was no additional advantage when using a shunting procedure. ${ }^{[9,20]}$ Calligaro and colleagues [21,22] reported that adequate carotid perfusion is provided if the carotid stump pressure is above $40 \mathrm{mmHg}$, whereas some authors stated that the stump pressure above 25 $\mathrm{mmHg}$ is sufficient. Bicer et al. ${ }^{[23]}$ emphasized that the carotid endarterectomy could be performed with low morbidity and mortality without shunting by providing normocapnia, controlled backflow from the internal carotid artery, and controlled hypertension. We noted that the stump pressure was above $40 \mathrm{mmHg}$ and no shunting was required in our cases.

It was reported that almost half of the patients, who undergo carotid endarterectomy, have coronary artery disease. In the previous studies, synchronous surgery for the carotid endarterectomy, and the coronary bypass was recommended in these patients. ${ }^{[24,25]}$ The CAS causes nearly one-third of the post-CABG stroke cases. Postoperative stroke is a major source of morbidity and mortality in patients undergoing CABG. ${ }^{[2]}$ Our results indicated that no difference existed concerning major complications of surgery between the patients undergoing simultaneous CEA/CABG and those undergoing only CEA. 
In the current study, we may have some limitations since we have performed a retrospective analysis, and therefore, we could make a clear conclusion regarding which surgical method is safer. Moreover, we had a relatively small case number, which made it hard to detect the subtle differences in complication rates. Indeed, adverse event rates were quite small in this study. On the other hand, we did our best to evaluate the complete picture of the perioperative phase of these patients, who underwent the CEA. We also presented a detailed report regarding surgical methods, some aspects of which are still debatable.

In conclusion, based on the retrospective analysis of the CEA, our results verified comparable safety of the CEA either with PA or with the PC method in contrast to the previous studies. Moreover, the restenosis, perioperative stroke, and mortality rates did not differ between the patient groups. Further studies are needed to end the ongoing debates on technically choose of better procedures.

\section{ETHICAL DECLARATIONS}

Ethics Comittee Approval: The study was carried out with the permission of Kayseri City Training and Educational Hospital Clinical Research Ethical Committee.

Informed Consent: Because the study was designed retrospectively, no written informed consent form was obtained from patients.

Status of Peer-review: Externally peer-reviewed.

Conflict of Interest Statement: The authors have no conflicts of interest to declare.

Financial Disclosure: The authors declared that this study has received no financial support.

Author Contributions: All of the authors declare that they have all participated in the design, execution, and analysis of the paper, and that they have approved the final version.

\section{REFERENCES}

1. Hidiroglu M, Cetin L, Kunt A, Karakisi O, Kuecueker A, Sener E. Early results of carotid endarterectomy for carotid artery diseases. Turkish Journal of Thoracic and Cardiovascular Surgery 2010;18(3):190-5.

2. Barnett HJM, Taylor DW, Haynes RB, et al. Beneficial effect of carotid endarterectomy in symptomatic patients with high-grade carotid stenosis. N Engl J Med 1991;325(7):445-53.

3. Eastcott $\mathrm{HH}$, Pickering GW, Rob CG. Reconstruction of internal carotid artery in a patient with intermittent attacks of hemiplegia. Lancet 1954;267(6846):994-6.

4. Liapis CD, Bell PR, Mikhailidis D, et al. ESVS guidelines. Invasive treatment for carotid stenosis: indications, techniques. Eur J Vasc Endovasc Surg 2009;37:1-19.

5. Muto A, Nishibe T, Dardik H, Dardik A. Patches for carotid artery endarterectomy: current materials and prospects. J Vasc Surg 2009;50(1):206-13.

6. Bond R, Rerkasem K, Naylor AR, Aburahma AF, Rothwell PM. Systematic review of randomized controlled trials of patch angioplasty versus primary closure and different types of patch materials during carotid endarterectomy. J Vasc Surg 2004;40(6):1126-35.
7. Rosenthal D, Archie JP Jr., Garcia-Rinaldi R, et al. Carotid patch angioplasty: immediate and long-term results. J Vasc Surg 1990;12(3):326-33.

8. Barnett HJ, Taylor DW, Eliasziw M, et al. Benefit of carotid endarterectomy in patients with symptomatic moderate or severe stenosis. North American Symptomatic Carotid Endarterectomy Trial Collaborators. N Engl J Med 1998;339(20):1415-25.

9. Melgar MA, Mariwalla N, Madhusudan H, Weinand M. Carotid endarterectomy without shunt: the role of cerebral metabolic protection. Neurol Res 2005;27(8):850-6.

10. Aboyans V, Ricco J-B, Bartelink M-LEL, et al. Editor's Choice - 2017 ESC Guidelines on the Diagnosis and Treatment of Peripheral Arterial Diseases, in collaboration with the European Society for Vascular Surgery (ESVS). European Journal of Vascular and Endovascular Surgery 2018;55(3):30568.

11. Byrne J, Feustel P, Darling RC, 3rd. Primary closure, routine patching, and eversion endarterectomy: what is the current state of the literature supporting use of these techniques? Semin Vasc Surg 2007;20(4):226-35.

12. Dirrenberger RA, Sundt TM, Jr.. Carotid endarterectomy. Temporal profile of the healing process and effects of anticoagulation therapy. J Neurosurg 1978;48(2):201-19.

13. Rerkasem K, Rothwell PM. Patch angioplasty versus primary closure for carotid endarterectomy. Cochrane Database Syst Rev 2009; Issue 4. Art. No:Cd000160.

14. Huizing E, Vos CG, Hulsebos RG, van den Akker PJ, Borst GJ, Unlu C. Patch Angioplasty or Primary Closure Following Carotid Endarterectomy for Symptomatic Carotid Artery Stenosis. Surg J (N Y) 2018;4(2):e96-e101.

15. Huizing E, Vos CG, van den Akker PJ, Schreve MA, de Borst GJ, Unlu C. A systematic review of patch angioplasty versus primary closure for carotid endarterectomy. J Vasc Surg 2019;69(6):1962-74.

16. Golledge J. Commentary. Carotid artery plaque composition--relationship to clinical presentation and ultrasound B-mode imaging. Eur J Vasc Endovasc Surg 2011;42(1):39-40.

17. Clagett GP, Patterson CB, Fisher DF, Jr., et al. Vein patch versus primary closure for carotid endarterectomy. A randomized prospective study in a selected group of patients. J Vasc Surg 1989;9(2):213-23.

18. Rerkasem K, Rothwell PM. Systematic review of randomized controlled trials of patch angioplasty versus primary closure and different types of patch materials during carotid endarterectomy. Asian J Surg 2011;34(1):32-40.

19. Li X, Guo Y, Ziegler KR, et al. Current usage and future directions for the bovine pericardial patch. Ann Vasc Surg 2011;25(4):561-8.

20. Samson RH, Showalter DP, Yunis JP. Routine carotid endarterectomy without a shunt, even in the presence of a contralateral occlusion. Cardiovasc Surg 1998;6(5):475-84.

21. Archie JP Jr. Technique and clinical results of carotid stump back-pressure to determine selective shunting during carotid endarterectomy. J Vasc Surg 1991;13(2):319-26.

22. Calligaro KD, Dougherty MJ. Correlation of carotid artery stump pressure and neurologic changes during 474 carotid endarterectomies performed in awake patients. J Vasc Surg 2005;42(4):684-9.

23. Biçer M, Davit S, Yanar M, et al. Carotid endarterectomy with checking back bleeding under controlled hypertension without use of shunting: experience of a single center. Uludağ Üniversitesi Tıp Fakültesi Derg $2011 ; 37(1): 1-5$

24. Salasidis GC, Latter DA, Steinmetz OK, Blair JF, Graham AM. Carotid artery duplex scanning in preoperative assessment for coronary artery revascularization: the association between peripheral vascular disease, carotid artery stenosis, and stroke. J Vasc Surg 1995;21(1):154-60.

25. Yıldırım T, Akgün S, Sur H, Kınıkoğlu H, Bilgin F, Arsan S. Short-term results of simultaneous carotid endarterectomy and myocardial revascularization. Turkish Journal of Thoracic and Cardiovascular Surgery 2004;12(3):156-60. 